\title{
Innovative Method for Water Deiron lons Using Capillary Material
}

\author{
Inna Trus ${ }^{1 *}$, laroslav Radovenchyk 1 , Vita Halysh ${ }^{1}$, Evhen Chuprinov², \\ Daniel Benatov', Hlushko Olena', Ludmila Sirenko'
}

1 Department of Ecology and Technology of Plant Polymers, Faculty of Chemical Engineering, National Technical University of Ukraine, Igor Sikorsky Kyiv Polytechnic Institute, Peremogy Avenu 37/4, 03056 Kyiv, Ukraine

2 Department of Metallurgical Technologies, State University of Economics and Technology, 5, Stepana Til gi str., 50006, Kryvyi Rih, Ukraine

* Corresponding author's e-mail: inna.trus.m@gmail.com

\begin{abstract}
Among all known inorganic pollutants of wastewater and natural water that adversely affect water bodies, different living organisms and human beings, iron compounds are the most common. Before discharging the wastewater into water bodies, it is important to remove iron ions from wastewater. The application of capillary materials in water and wastewater treatment is a promising direction of ecology and technology. The capillary properties of materials allow the development of quite simple, autonomous, highly efficient and energy-saving systems for water purification. The aim of the present paper was the investigation of the influence of the basic conditions of the filtration process with the application of capillary materia on the efficiency of iron ions removal. The initial concentration of the model solution, $\mathrm{pH}$ and temperature of the filtration process, as well as the contact area of the liquid phase with oxygen of the air were studied. The proposed method is appropriate for the treatment of water in the concentration range from 5 to $10 \mathrm{mg} / \mathrm{dm}^{3}$ with an optimum $\mathrm{pH}$ in the range of 4-7. The experimental data showed high efficiency of capillary materials application, providing sufficient removal of iron ions from low concentrated solutions, compared to the traditional method of precipitation. The main advantage of the capillary materials is the simplicity of their application, quite high degree of purification and there no need to consume electricity or additional reagents, which allows creating autonomous water treatment facilities and plants.
\end{abstract}

Keywords: iron ions, capillary materials, purification, treatment

\section{INTRODUCTION}

Today, due to the discharge of large quantities of insufficiently treated and untreated effluents, the pollution of surface as well as groundwater, which are sources of water supply, take place (Kyrii et al. 2020, Rusdiyanto et al. 2021, Sillberg et al. 2021, Trus and Gomelya 2021). Large areas do not have sufficient water resources or they are in poor quality (Walczak 2021., Pichura et al. 2020). Therefore, in some industrial regions of Ukraine (Donetsk, Luhansk region and others), the water supply issues can be solved using large volumes of mine wastewater after sufficient treatment (Buzylo et al. 2020, Trus et al. 2020).

Due to rapid development of agroindustrial complex, the related high level of technogenic impact on the landscape is observed. That is why underground sources of water can be regarded as the only available sources of drinking water (Remeshevska et al. 2021, Hryniuk \& Arkhypova 2018). However, during the last decades, the negative and often uncontrolled anthropogenic effect, which leads to the pollution of groundwater with different pollutants throughout the territory of Ukraine, is recorded (Korchemlyuk et al. 2019, Gorova et al. 2013). Heavy metal ions can be accumulated and therefore they are the most dangerous pollutants (Monastyrov et al. 2019, Custodio and Peñaloza 2021).

Nowadays, in Ukraine and in many parts of the world, the population consumes the drinking water that does not meet the requirements, established by the regulatory document (DSanPIN 
2.2.4-171-10). High environmental pollution with different compounds makes it possible for heavy metals (chromium, iron, copper, nickel, zinc, lead, etc.) to enter the water supply system (Koedrith et al. 2013, Peligro et al. 2016, Carolin et al. 2017, Vardhan et al. 2019). Thus, the most important problem for the present is the development of innovative methods of water purification from heavy metals in the systems of water treatment. Iron ions are the most common components in water, due to the regional, climatic and landscape features of the area (Biela et al. 2016, Chowdhury et al. 2016, Fu and Wang 2011). Iron ions adversely affect humans and other living organisms, causing a variety of diseases, parameters of natural water, precipitated on the surface of equipment causing them to break. Therefore, during the discharge of wastewater into surface water bodies, for further consumption of natural waters, it is necessary to remove iron ions from the water. In Ukraine, according to the normative document, the maximum permissible concentration (MPC) of iron ions is $0.2 \mathrm{mg} / \mathrm{dm}^{-3}$. Some regions in Ukraine are characterized by an increased iron content in the range from 0.5 to 30 mg. (Shevchenko et al. 2013). This is a significant reason for the continuous growth of infectious, carcinogenic diseases, which ultimately leads to a decrease in the birth rate and expectancy of life of the population in Ukraine (Gomelya et al. 2021).

The presence of iron ions in groundwater is connected with a wide distribution of the iron compounds in nature. Iron content of the Earth's crust reaches up to $5 \%$. Because of this fact, the metal ions are found in all water sources both in surface water and groundwater. Natural water contains iron in the form of two- and trivalent ions, complexes with humates and fulvic acids, colloids of organic and inorganic origin, as well as in the form of highly dispersed suspensions. The content of iron ions is connected with the features of the territory. The excess of iron is characteristic for almost all reservoirs of natural fresh water, regardless of belonging to the artesian basin. The iron ions concentration often exceeds the maximum permissible levels $\left(0.2 \mathrm{mg} \mathrm{dm}^{-3}\right.$ and $1.0 \mathrm{mg}$ $\mathrm{dm}^{-3}$ for tap and well water, respectively) by $5-20$ times and even more, and in groundwater the excess increases sometimes by 40-60 time,s up to $12-18 \mathrm{mg} \mathrm{dm}^{-3}$. Even low concentrations of iron ions $\left(0.4 \mathrm{mg} \mathrm{dm}^{-3}\right)$ can cause stains on equipment and other surfaces. Higher concentrations cause the characteristic metallic flavor of water (Ellis et al. 2000, Leszczyński 2019).

Therefore, the search for efficient methods of water treatment from iron ions, which will reduce its concentration to the permissible levels, is an urgent task nowadays (Trus et al. 2021). Different methods can be used for the purpose of iron ions removal from surface and underground waters, such as aeration, ion exchange (Gomelya et al. 2017, Al-Anberet et al. 2008), water filtering through pyrolusite, liming, coagulation, different oxidizing methods with the application of ozone, oxygen, hydrogen peroxide, chlorine and potassium permanganate (Ellis et al. 2000, Munter et al. 2005), ferrite method method (Radovenchik et al. 2001, Han et al. 2016), biological (Pacini et al. 2005), electrocoagulation (Trokhymenko et al. 2020, Trus et al. 2020, Gorova et al. 2013), adsorption with the application of palygorskite (Melnyk et al. 2015) and zeolite (Sabadash et al. 2017), biosorbents (Halysh et al. 2020) and modified filters (Gomelya et al. 2016, Trus et al. 2019), membrane methods (Choo et al. 2005, Korchef et al. 2009).

The efficiency of the process greatly depends on the experimental conditions, for instance, $\mathrm{pH}$, reaction temperature and initial concentration of iron ions in the solution (Heuss-Aßbichler et al. 2016).

The development and application of an effective technology of water demineralization will help to provide technogenic and environmental safety (Trus et al. 2017, Gomelya et al. 2014, Gomelya et al. 2014). The method of iron removal from water can be chosen depending on the chemical composition of water, productivity of the equipment, and the necessary degree of removal, etc.

Nowadays, the filtration with the application of capillary materials can be regarded as an alternative method of iron ions removal (Radovenchyk et al. 2021). It is a one of the promising directions in ecology for water treatment, which is based on physical phenomena. The application of the capillary filtration method allows developing quite simple, autonomous, highly efficient and energy-saving technology for natural water treatment and wastewater purification.

Capillary action is widespread in nature, for instance, the Earth's crust is a porous material and the processes of liquids moving in soil pores were far and wide studied. It was found that because of the presence of small pores, the water in the soil can move at considerable distances and rise to a certain level in the groundwater (Braslapskiy 1987, Plotnikov 1990). 
The capillary materials can be applied to conduct simultaneous deep and efficient water treatment from different types of pollutants such as suspended substances, microorganisms, organic and inorganic compounds (http://www. aquaphor.ua/aqualen).

The capillary effect, together with other physical and chemical processes, has become quite widespread in different branches of industries. Some chemical methods of analysis are based on the capillary phenomenon, different equipment and facilities contain capillary tubes or materials. At the same time, the technologies based on capillary action as the main technological process in the water treatment or water preparation are absent. Therefore, the research and development work in this direction is quite acute and promising.

The aim of the present study is an assessment of the efficiency of capillary materials application for water purification from iron ions at different values of technological parameters of the process.

\section{MATERIALS AND METHODS INVESTIGATION}

Model solutions of natural water were used in this study as objects of investigation. The concentrations of iron ions in these solutions were $1,2,5,10$ and $15 \mathrm{mg} \mathrm{dm}^{-3}$. The material of the filter was chosen depending on its properties and chemical composition of the model solution. Experiments were conducted with the application of cotton fabric as a capillary filter. Cotton fabric was chosen due to its availability and low cost, compared to other filtering materials.

The filtration process was carried out with the application of material with capillary as shown in Figure 1. A tourniquet of cotton fabric (2) was placed into a flask (1) which contained a model solution of the certain composition. Thus, one end of the filtering material was placed into the model solution and the other one was pulled out of the flask. Due to the surface tension of the liquid, it rises through the capillaries of the fabric and because of the difference in liquid phase levels at the ends of the filter, the liquid flows into another flask (3). The purified water solution was collected and analysed.

Model solutions of divalent iron were used and prepared by dissolution of ammonium iron (II) sulfate hexahydrate $\left(\mathrm{Fe}\left(\mathrm{NH}_{4}\right)_{2}\left(\mathrm{SO}_{4}\right)_{2}\right)$. The iron ions content in the solutions was determined using the spectrophotometric method by means of sulfosalicylic acid. The $\mathrm{pH}$ of the model solutions was adjusted by a $\mathrm{pH}-$ meter with solutions of ammonia and hydrochloric acid.

Together with the capillary filtration, a classical precipitation of the model solutions were carried out to reduce the iron ion concentrations.

In order to evaluate the reduction of iron ion concentrations, the efficiency of the removal was calculated according to the formula:

$$
Z=\frac{C_{0}-C_{f}}{C_{0}} \cdot 100, \%
$$

where: $\mathrm{C}_{0}$-initial concentrationofironions, $\mathrm{mgdm}^{-3}$, $\mathrm{C}_{\mathrm{f}}$ - final concentration of iron ions, $\mathrm{mg} \mathrm{dm}^{-3}$.

The efficiency of iron ions removal during transition of $\mathrm{Fe}^{2+}$ into the $\mathrm{Fe}^{3+}$ form was calculated as follows:

$$
\mathrm{E}=\frac{\mathrm{C}_{0}\left(\mathrm{Fe}^{2+}\right)-\mathrm{C}_{\mathrm{f}}\left(\mathrm{Fe}^{2+}\right)}{\mathrm{C}_{0}\left(\mathrm{Fe}^{2+}\right)} \cdot 100, \%
$$

where: $\mathrm{C}_{0}\left(\mathrm{Fe}^{2+}\right)$ - initial concentration of $\mathrm{Fe}^{2+}$, $\mathrm{mg} \mathrm{dm}{ }^{-3} ; \mathrm{C}_{\mathrm{f}}\left(\mathrm{Fe}^{2+}\right)$ - final concentration of $\mathrm{Fe}^{2+}, \mathrm{mg} \mathrm{dm}^{-3}$.

\section{RESULTS AND DISCUSSION}

An important factor in the process of water deironing by filtration with the application of capillary materials is the density of capillary filters.

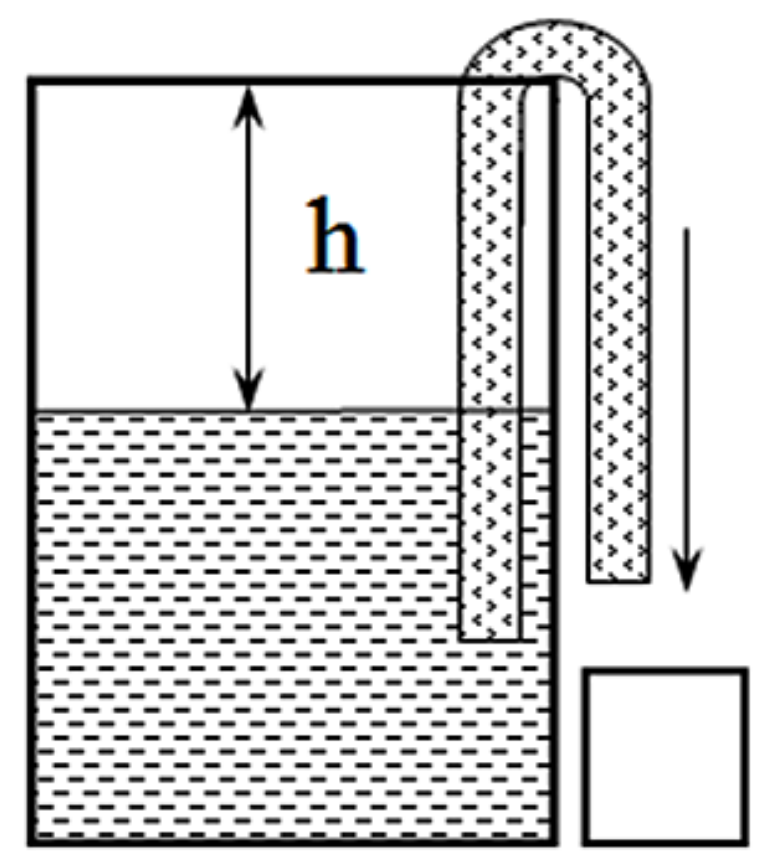

Figure 1. Scheme of the filtration facility with the application of fabric material as a filter 


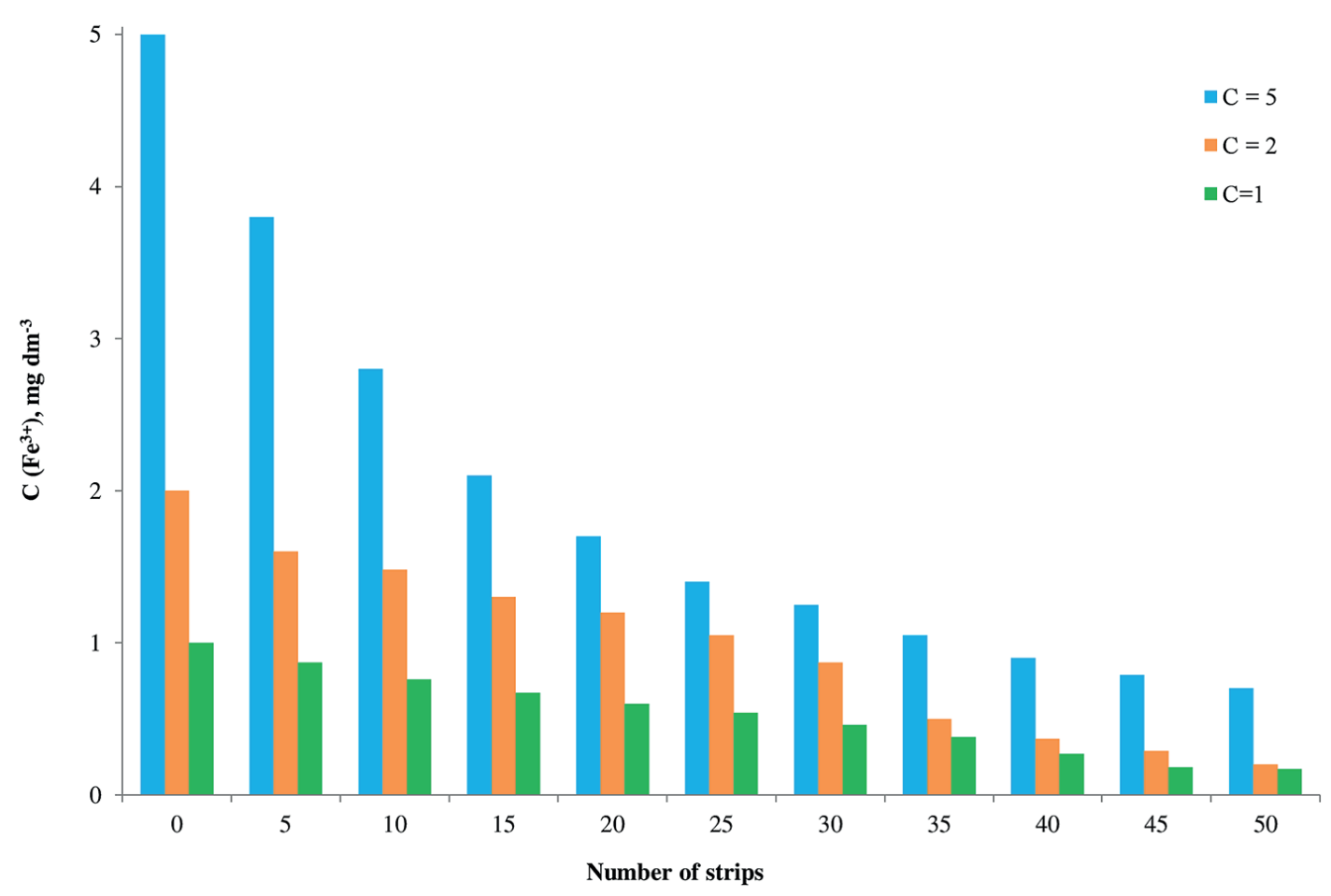

Figure 2. The effect of capillary material density on the process of water deironing at initial iron concentrations: 1,2 and $5 \mathrm{mg} / \mathrm{dm}^{3}$

Therefore, the influence of capillary material density on the deironing process was studied at the first stage. The results of the studies showed that at initial iron concentrations of 1.0, 2.0 and $5.0 \mathrm{mg} /$ $\mathrm{dm}^{3}$, the increase in the number of strips of cotton fabric from 5 to 50 has little effect on the process. At these concentrations, there is approximately the same dynamics of reducing the concentration of total iron in the studied samples. Therefore, the density of capillary filters affects only the time of the process of iron ions removal (Fig. 2).

In further research, the possibility of cotton fabric application to reduce the iron ion concentrations in model solutions was investigated. For this purpose, the model solution with the initial iron ions concentration $10 \mathrm{mg} \mathrm{dm}^{-3}$ was used. The process temperature was $20^{\circ} \mathrm{C}$ and $\mathrm{pH}$ of the solution was 6.8. Determination of the residual concentration of iron ions in the solutions was carried out in 5, 30, 60, 90 and 120 minutes from the beginning of the experiment. As it can be seen from Figure 3 , the efficiency of the application of cotton fabric for the iron removal from water solutions is high, compared to the classic preparation process. The results of some experiments show minor errors because of the insignificant sorption of iron ions onto cotton fabric. The sorption is quite weak, so it does not affect the results and can be ignored.
As can be seen from the data in Figure 3, the decreasing concentration of iron ions occurs more efficiently during the use of simple filter with capillary properties. Under the same conditions, the use of filters with capillary properties ensured a significant decrease in the $\mathrm{Fe}^{2+}$ and $\mathrm{Fe}^{3+}$ ions concentration. For instance, the concentration of $\mathrm{Fe}^{2+}$ was decreased to $1.4 \mathrm{mg} \mathrm{dm}^{-3}$ with the application of capillary filter during 1 hour. At the same time, during precipitation the concentration of $\mathrm{Fe}^{2+}$ decreased to $8.7 \mathrm{mg} \mathrm{dm}^{-3}$. This proves the prospects for further application of capillary filter for the purpose of water treatment.

A great number of factors influence the efficiency of the iron ions removal by capillary filtration. The influence of $\mathrm{pH}$ of the solution on the reduction in the concentration of iron ions during filtration was also determined. It is known that at different values of $\mathrm{pH}$ of the solution, the iron ions stay in various forms. The model solution with the initial iron ions concentration $5 \mathrm{mg} \mathrm{dm}^{-3}$ was used and the results are given in Figure 4. Model solutions with $\mathrm{pH} \mathrm{4,7}$ and 10 were investigated in experiments

While analyzing the obtained results, it can be concluded that promotion of the transition of $\mathrm{Fe}^{2+}$ ions into $\mathrm{Fe}^{3+}$ form takes place during filtering. The dependence of the efficiency of iron removal 

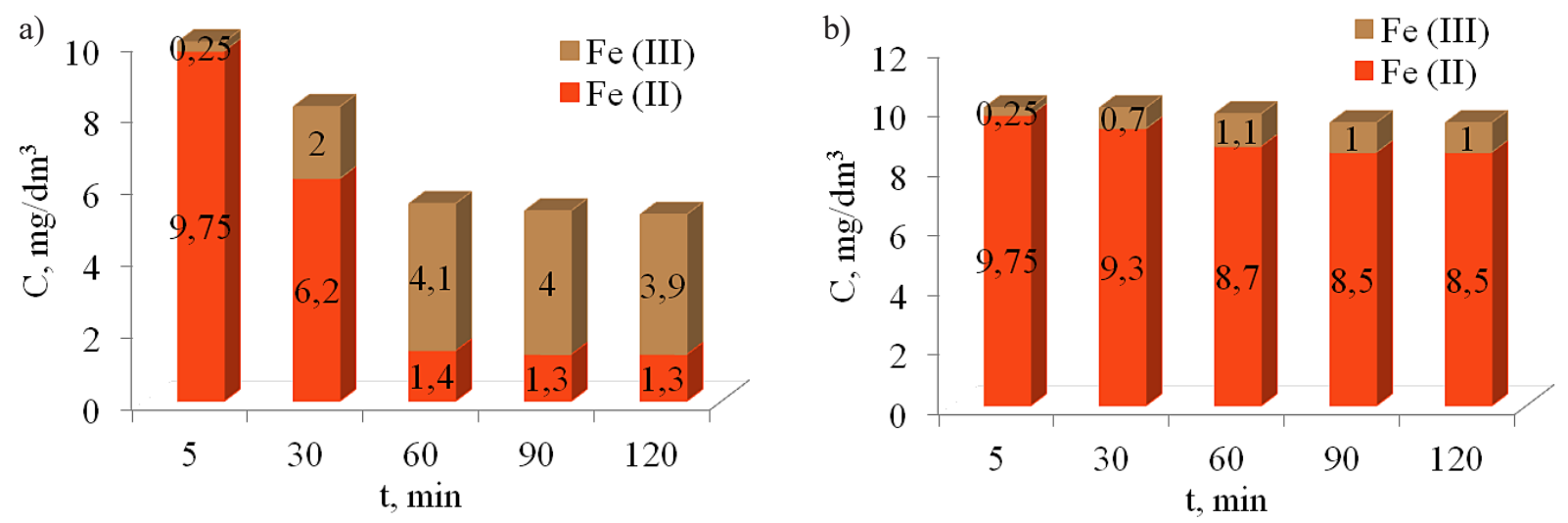

Figure 3. Iron ions removal during filtering (a) and precipitation (b):

$1-\mathrm{Fe}^{2+}$ concentration, $2-\mathrm{Fe}^{3+}$ concentration

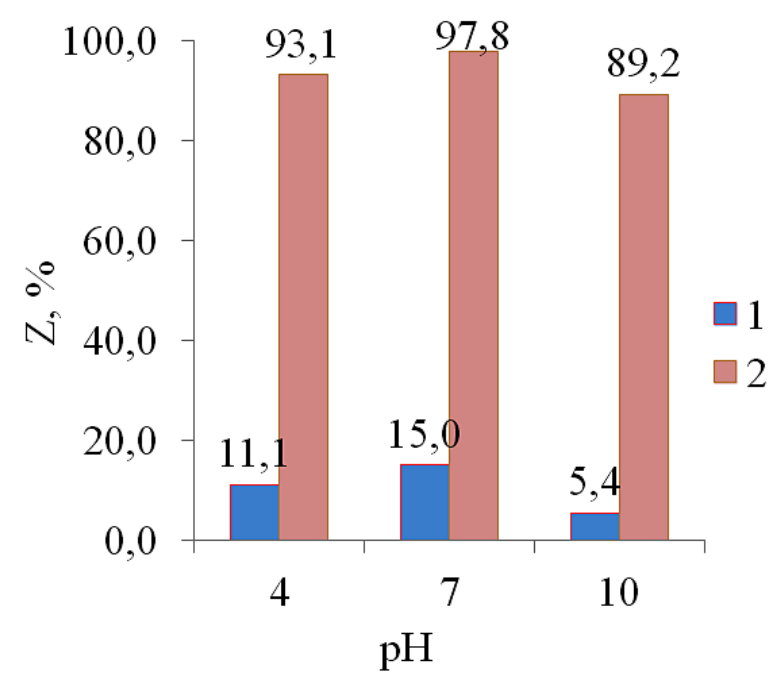

Figure 4. Efficiency of divalent iron removal at different $\mathrm{pH}$ values during precipitation (1) and filtration (2)

during precipitation $\left(\mathrm{Y}_{\mathrm{s}}\right)$ and during filtration $\left(\mathrm{Y}_{\mathrm{c}}\right)$ on $\mathrm{pH}$ of the solution $(\mathrm{X})$ can be described by the following questions:

$$
\begin{gathered}
Y_{S}=15.1-9.55 \cdot X+0.75 \cdot X^{2} \\
Y_{C}=66.144+9.6944 \cdot X-0.73889 \cdot X^{2}
\end{gathered}
$$

The maximum values of $Y_{s}$ and $Y_{c}$ are observed at $\mathrm{X}$ equal to 6.35 and 6.55 , respectively. It can be concluded that the optimal $\mathrm{pH}$ for the effective transition of $\mathrm{Fe}^{2+}$ ions into $\mathrm{Fe}^{3+}$ form is 6.55 and 6.35 for capillary filtering method and precipitation, respectively. The efficiency of iron ion removal at an optimal $\mathrm{pH}$ value on cotton fabric reaches $97 \%$, while during precipitation the value of this parameter is only $15 \%$.

It is also important to evaluate the influence of the initial concentration of iron in the model water solution on the efficiency of its removal, so the experiments were conducted with the application of aqueous solutions with different initial concentrations of ions. The model solutions with the concentration of iron ions 1,10 and $15 \mathrm{mg} \mathrm{dm}^{-3}$ were used and the results are given in Figure 5.

According to the results, the dependence of the efficiency of iron removal on its initial concentration was established. As it can be seen, the efficiency of iron concentration by capillary filtering during laboratory experiments reduced with the increase in initial iron concentration. At the same time, the efficiency increases with the contact time prolongation indicating the need to apply capillary materials with more porous structure or prolonged contact time in case of high iron ion concentration in the solution.

It is known that the contact of water with oxygen of air affects the transition processes of $\mathrm{Fe}^{2+}$ ions into $\mathrm{Fe}^{3+}$ form. Therefore, in further studies,

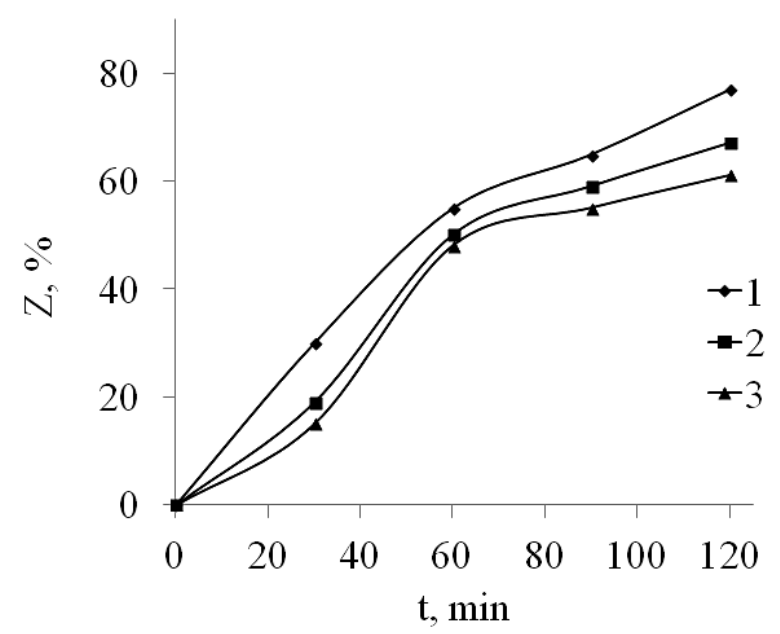

Figure 5. Efficiency of iron ions removal during capillary filtration of the model solutions with different initial concentration: $1-1 \mathrm{mg} \mathrm{dm}^{-3} ; 2-10 \mathrm{mg} \mathrm{dm}^{-3}$; $3-15 \mathrm{mg} \mathrm{dm}^{-3}$ 


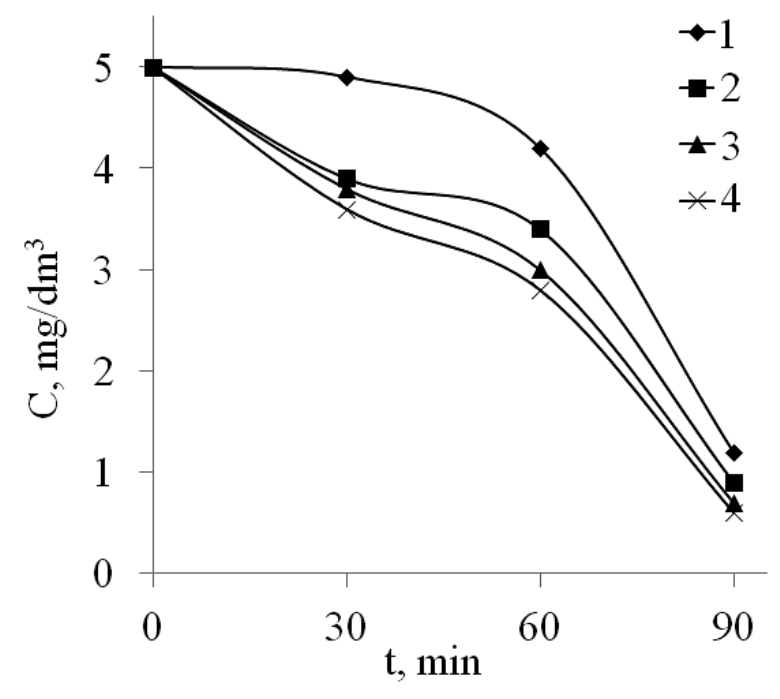

Figure 6. Dependence in the concentration of iron ions during capillary filtration on different contact areas of solutions with air: $1-30 \mathrm{~cm}^{2} ; 2-45 \mathrm{~cm}^{2} ; 3-60 \mathrm{~cm}^{2}$; $4-75 \mathrm{~cm}^{2}$
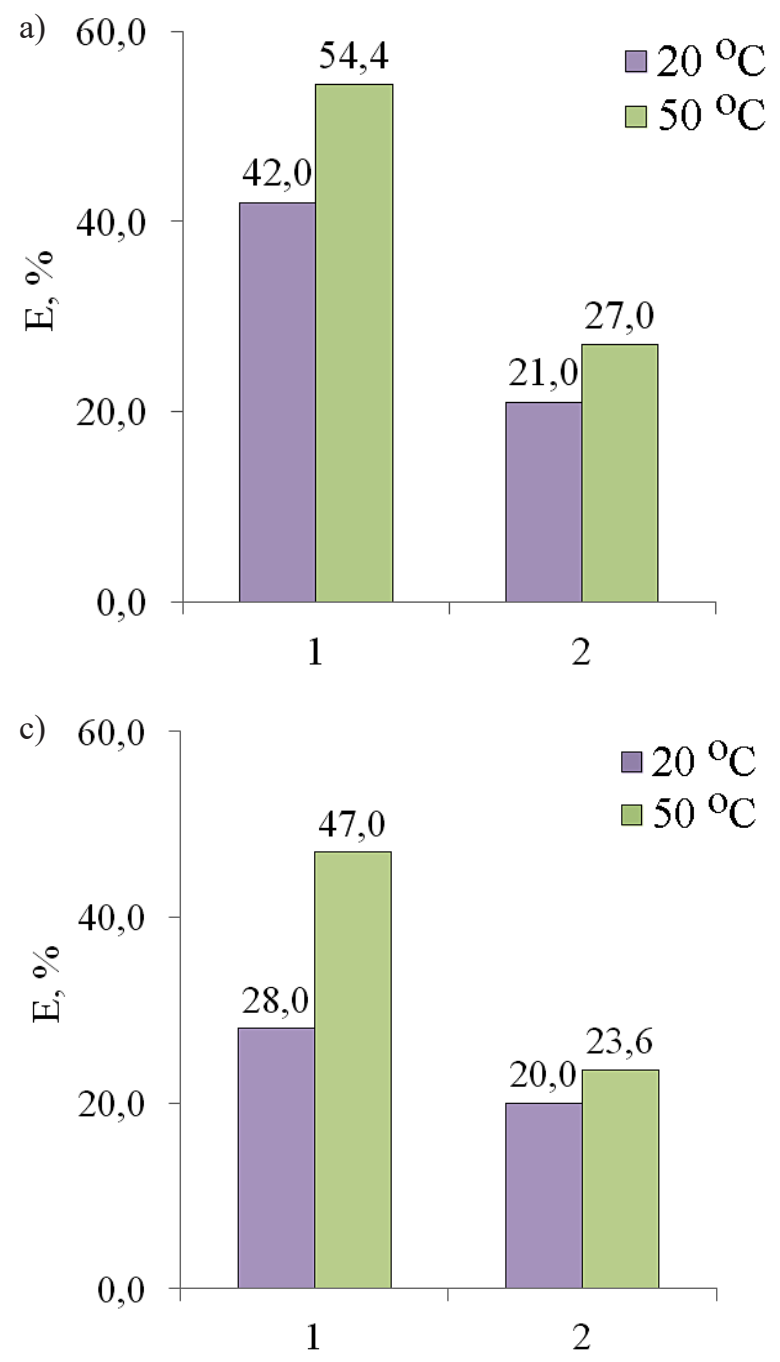

the change in the iron content in the model solution was investigated with the application of capillary materials of different surface areas. The contact surface of the model solution with air was $30,45,60$ and $75 \mathrm{~cm}^{2}$. The initial concentration of iron ions in solution was $5 \mathrm{mg} \mathrm{dm}^{-3}$. In each experiment, the area of the tourniquet of the capillary filter was different. Thus, the area of the contact of the model solution with air was controlled. The results are given in Figure 6.

Figure 6 shows that the variation in contact area affects the iron ions concentration and the speed of solutions transportation.

The contact area, as well as the fluid speed significantly affect the transition of iron ions. The larger contact area of water with air, the more intense reduction in iron content is observed. The most intense decrease in the concentration of iron was observed at a contact area of $75 \mathrm{~cm}^{2}$.
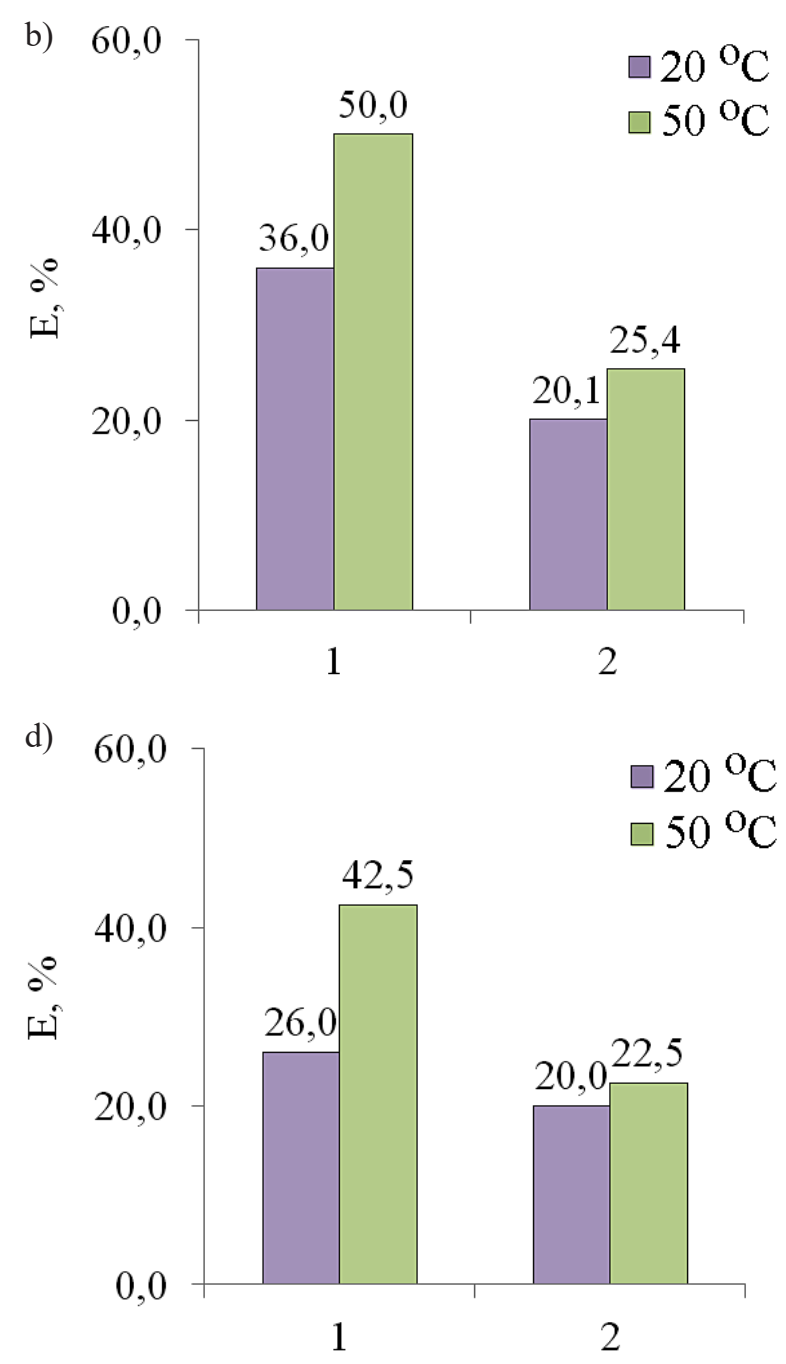

Figure 7. Efficiency of the transition of $\mathrm{Fe}^{2+}$ to $\mathrm{Fe}^{3+}$ form at different temperature of model solution during capillary filtration (1) and precipitation (2) for different initial concentration of model solution: $\mathrm{a}-1 \mathrm{mg} \mathrm{dm}^{-3} ; \mathrm{b}-2 \mathrm{mg} \mathrm{dm}^{-3} ; \mathrm{c}-5 \mathrm{mg} \mathrm{dm}^{-3} ; \mathrm{d}-10 \mathrm{mg} \mathrm{dm}^{-3}$ 
The temperature is also an important parameter that affects the processes of iron ions transition from one form to another. Therefore, the next stage of the performed research work was to evaluate the influence of process temperature on efficiency or iron removal. The research work was carried out at the temperature 20 and $50^{\circ} \mathrm{C}$. The concentration of $\mathrm{Fe}^{3+}$ in water was measured in 30 minutes and the results of the experiments are given in Figure 6.

As it can be seen, the temperature substantially affects the processes of iron removal from water. At $20^{\circ} \mathrm{C}$ the processes of transition of $\mathrm{Fe}^{2+}$ to $\mathrm{Fe}^{3+}$ are less pronounced if compared to increased temperature. The process of iron removal during the capillary filtering through the cotton fabric significantly depends on time. At a temperature of $50^{\circ} \mathrm{C}$, a more intense oxidation of divalent iron ions to trivalent occurs.

\section{CONCLUSIONS}

1. The application of capillary materials in the treatment of water of different origin is highly efficient. This method of iron ions removal can be regarded as an alternative to such methods as aeration or precipitation.

2. It was found that the efficiency of capillary materials application for oxidation of iron ions is much higher when compared to traditional precipitation. The optimum value of $\mathrm{pH}$ for the effective iron ions oxidation is 6.55 and 6.35 for capillary filtration and precipitation, respectively.

3. It was investigated that the transition of $\mathrm{Fe}^{2+}$ to $\mathrm{Fe}^{3+}$ significantly depends on the contact area of water solution with air. Reduction of the total iron content is directly proportional to the contact area. The larger the contact area of water with air, the more intense reduction in iron content occurs. Deironing of water at an area of contact of $30,45,60$ and $75 \mathrm{~cm}^{2}$ was studied and the value of $75 \mathrm{~cm}^{2}$ shows the best result during the water treatment from iron ions.

4. It was shown that with the increase in the initial concentration of iron in water, the decrease in efficiency of iron ions removal is observed. The increase in water temperature during treatment intensifies the transition of $\mathrm{Fe}^{2}+$ to $\mathrm{Fe}^{3+}$ both for capillary filtering and for precipitation.
5. During precipitation, the increase in temperature of the solution from 20 to $50^{\circ} \mathrm{C}$ leads to a slight increase in the transition processes of $\mathrm{Fe}^{2+}$ to $\mathrm{Fe}^{3+}$. The increase in temperature of the solution during capillary filtration leads to more intense transition of iron ions compared to classical precipitation.

6. The application of treatment based on the capillary filtration with the use of cheap and available raw material is a quite simple, which can contribute to the creation of new integrated technology for water purification and wastewater treatment from iron ions.

\section{REFERENCES}

1. Al-Anber M., A. Al-Anber Z. 2008. Utilization of natural zeolite as ion-exchange and sorbent material in the removal of iron. Desalination, 225, 1-3, 70-81. doi.org/10.1016/j.desal.2007.07.006

2. Biela R., Kucera T. 2016. Efficacy of sorption materials for nickel, iron and manganese removal from water. Procedia Eng., 162, 56-63. DOI: 10.1016/j. proeng.2016.11.012

3. Braslapskiy V.A. Capillary processes in textile materials. Moscow, Legprombytizdat, 1987. (in Russian)

4. Buzylo V., Pavlychenko A., Savelieva T., Borysovska O. 2018. Ecological aspects of managing the stressed-deformed state of the mountain massif during the development of multiple coal layers, $\mathrm{Pa}$ per presented at the E3S Web of Conferences, 60 . DOI: $10.1051 / \mathrm{e} 3$ sconf $/ 20186000013$.

5. Carolin C.F., Kumar P.S., Saravanan A., Joshiba G. J., Naushad M. 2017. Efficient techniques for the removal of toxic heavy metals from aquatic environment: A review. Journal of Environmental Chemical Engineering, 5(3), 2782-2799. DOI: 10.1016/j. jece.2017.05.029

6. Choo K.H., Lee H., Choi S.J. 2005. Iron and manganese removal and membrane fouling during UF in conjunction with prechlorination for drinking water treatment. Journal of Membrane Science, 267, 18-26. DOI: 10.1016/j.memsci.2005.05.021

7. Chowdhury S., Mazumder M. A. J., Al-Attas O., Husain T. 2016. Heavy metals in drinking water: Occurrences, implications, and future needs in developing countries. Science of The Total Environment, 569, 476-488. DOI: 10.1016/j.scitotenv.2016.06.166

8. Custodio M., Peñaloza R. 2021. Evaluation of the Distribution of Heavy Metals and Arsenic in Inland Wetlands (Peru) Using Multivariate Statistical Methods. Ecol. Eng. Environ. Technol., 22(3), 104-111. DOI: 10.12912/27197050/135522 
9. Ellis D., Bouchard C., Lantagne G. 2000. Removal of iron and manganese from groundwater by oxidation and microfiltration. Desalination, 130, 3, 255-264. DOI: 10.1016/S0011-9164(00)00090-4

10. Fu F., Wang Q. 2011. Removal of heavy metal ions from wastewaters: A review. Journal of Environmental Management, 92 (3), 407-418. DOI: 10.1016/j.jenvman.2010.11.011

11. Gomelya M., Tverdokhlib M., Shabliy T., Radovenchyk V., Linyucheva O. 2021. Sorbent-Catalyst for Acceleration of the Iron Oxidation Process. Journal of Ecological Engineering, 22(3), 221-230. DOI: $10.12911 / 22998993 / 133030$

12. Gomelya M., Trus I., Shabliy T. 2014. Application of aluminium coagulants for the removal of sulphate from mine water. Chemistry and Chemical Technology, 8, 2, 197-203. DOI: 10.23939/chcht08.02.197

13. Gomelya N., Ivanova V., Galimova V., et al. 2017. Evaluation of cationite efficiency during extraction of heavy metal ions from diluted solutions. EasternEuropean Journal of Enterprise Technologies, 5/6, 89, 4-10. DOI: 10.15587/1729-4061.2017.109406

14. Gomelya N., Tverdokhlib M. 2016. Research of efficiency of water purification-exchange resin from iron compounds using modified filter media. Eastern-European Journal of Enterprise Technologies, 2, 10, 47-52. DOI: 10.15587/1729-4061.2016.63608

15. Gomelya N.D., Trus I.N., Nosacheva Y.V. 2014. Water purification of sulfates by liming when adding reagents containing aluminum. Journal of Water Chemistry and Technology, 36, 2, 70-74. DOI: $10.3103 / \mathrm{S} 1063455 \mathrm{X} 14020040$

16. Gorova A., Pavlychenko A., Borysovs'ka O., Krups'ka L. 2013. The development of methodology for assessment of environmental risk degree in mining regions. Annual Scientific-Technical Colletion - Mining of Mineral Deposit, 207-209. DOI: $10.1201 / \mathrm{b} 16354-38$

17. Halysh V., Trus I., Nikolaichuk A., Skiba M., Radovenchyk I., Deykun I., Vorobyova V., Vasylenko I., Sirenko L. 2020. Spent Biosorbents as Additives in Cement Production. Journal of Ecological Engineering, 21, 2, 131-138. DOI: $10.12911 / 22998993 / 116328$

18. Han H., Sun W., Hu Y., Cao X., Tang H., Liu R., Yue T. 2016. Magnetite precipitation for iron removal from nickel-rich solutions in hydrometallurgy process. Hydrometallurgy, 165, 318-322. DOI: 10.1016/j.hydromet.2016.01.006

19. Heuss-Aßbichler S., Melanie J., Klapper D. et al. 2016. Recovery of copper as zero-valent phase and/ or copper oxide nanoparticles from wastewater by ferritization. Journal of Environmental Management, 181, 1-7. DOI: 10.1016/j.jenvman.2016.05.053

20. Hryniuk V.I., Arkhypova L.M. 2018. Regularity of effects of climatic changes on quality indicators of surface water of the Dniester basin. Naukovyi Visnyk Natsionalnoho Hirnychoho Universytetu, 3, 125-133. http://nbuv.gov.ua/UJRN/ Nvngu_2018_3_19

21. Koedrith P., Kim H., Weon J., Seo Y. R. 2013. Toxicogenomic approaches for understanding molecular mechanisms of heavy metal mutagenicity and carcinogenicity. International Journal of Hygiene and Environmental Health, 216(5), 587-598. DOI: 10.1016/j.ijheh.2013.02.010

22. KorchefA., Kerkeni I., Amor M.B., Galland S., Per$\sin$ F. 2009. Iron removal from aqueous solution by oxidation, precipitation and ultrafiltration. Desalin. Water Treat, 9, 1-8. DOI: 10.5004/dwt.2009.745

23. Korchemlyuk M., Arkhipova L., Kravchynskyi R.L., Mykhailyuk J.D. 2019. Anthropogenic influence from point and diffuse sources of pollution in the upper prut river basin. Naukovyi Visnyk Natsionalnoho Hirnychoho Universytetu, 1, 125-131. DOI: $10.29202 /$ nvngu/2019-1/12

24. Kyrii S., Dontsova T., Kosogina I., Astrelin I., Klymenko N., Nechyporuk D. 2020. Local wastewater treatment by effective coagulants based on wastes. Journal of Ecological Engineering, 21, 5, 34-41. DOI: $10.12911 / 22998993 / 122184$

25. Leszczyński J. 2019. Color Removal from Groundwater by Coagulation and Oxidation Processes. Journal of Ecological Engineering, 20(9), 138-144. DOI: $10.12911 / 22998993 / 112497$

26. Melnyk L., Bessarab O., Matko S., Malovanyy M. 2015. Adsorption of heavy metals ions from liquid media by palygorskite. Chemistry and Chemical Technology, 9, 4, 467-470. DOI: 10.23939/ chcht09.04.467

27. Monastyrov M., Prikhna T., Halbedel B., Kochetov G., Marquis F., Mamalis A., Prysiazhna O.2019. Eectroerosion dispersion, sorption and coagulaton for complex water purification; electroerosion waste recycling and manufacturing of metals, oxides and alloys nanopowders. Nanotechnology Perceptions, 15, 48-57. DOI: 10.4024/N24MO18A.ntp.15.01

28. Munter R., Ojaste H., Sutt J. 2005. Complexed iron removal from ground water. Journal of Environmental Engineering, 131, 7, 1014-1020. DOI: 10.1061/ (ASCE)0733-9372(2005)131:7(1014)

29. Pacini V.A., Ingallinella A.M., Sanguinetti G. 2005. Removal of iron and manganese using biological roughing up flow filtration technology. Water Research, 39, 18, 4463-4475. DOI: 10.1016/j. watres.2005.08.027

30. Peligro F.R., Pavlovic I., Rojas R., Barriga C. 2016. Removal of heavy metals from simulated wastewater by in situ formation of layered double hydroxides. Chemical Engineering Journal, 306, 1035-1040. DOI: 10.1016/j.cej.2016.08.054 
31. Pichura V., Potravka L., Skrypchuk P., Stratichuk N. 2020. Anthropogenic and Climatic Causality of Changes in the Hydrological Regime of the Dnieper River. Journal of Ecological Engineering, 21(4), 1-10. DOI: 10.12911/22998993/119521.

32. Plotnikov N.I. Groundwater is our wealth. Moscow, Nedra, 1990. (in Russian)

33. Radovenchik V.M., Korostyatinets V.D., Ivanenko E.I. 2001. Study of efficiency of iron ions extraction from aqueous solutions by ferrite method. Khimiya i Tekhnologiya Vody, 23(2), 172-176.

34. Radovenchyk I., Trus I., Halysh V., Krysenko T.,Chuprinov E., Ivanchenko A. 2021. Evaluation of Optimal Conditions for the Application of Capillary Materials for the Purpose of Water Deironing. Ecol. Eng. Environ. Technol., 22(2), 1-7. DOI: $10.12912 / 27197050 / 133256$

35. Remeshevska I., Trokhymenko G., Gurets N., Stepova O., Trus I., Akhmedova V. 2021. Study of the Ways and Methods of Searching Water Leaks in Water Supply Networks of the Settlements of Ukraine. Ecol. Eng. Environ. Technol., 22(4), 14-21. DOI: $10.12912 / 27197050 / 137874$

36. Rusdiyanto E., Sitorus S.R., Noorachmat B.P., Sobandi R. 2021. Assessment of the Actual Status of the Cikapundung River Waters in the DenselyInhabited Slum Area, Bandung City. Journal of Ecological Engineering, 22(11), 198-208. DOI: $10.12911 / 22998993 / 142916$

37. Sabadash V., Mylanyk O., Matsuska O., Gumnitsky J. 2017. Kinetic regularities of copper ions adsorption by natural zeolite. Chemistry and Chemical Technology, 11, 4, 459-462.

38. Shevchenko O., Kornienko S., Dihtyaruk O. 2013. Analysis of the reasons for the increase in the concentration of iron in the groundwater of the water intakes of Shepetivka. Visnyk, Kyiv, Kyiv National University named after Taras Shevchenko. (in Ukrainian)

39. Sillberg C.V., Kullavanijaya P., Chavalparit O. 2021. Water Quality Classification by Integration of Attribute-Realization and Support Vector Machine for the Chao Phraya River. Journal of Ecological Engineering, 22(9), 70-86. DOI: $10.12911 / 22998993 / 141364$

40. State sanitary norms and rules "Hygienic requirements for drinking water intended for human consumption" (DSanPIN 2.2.4-171-10). (in Ukrainian)
41. Trokhymenko G., Magas N., Gomelya N., Trus I., Koliehova A. 2020. Study of the Process of Electro Evolution of Copper Ions from Waste Regeneration Solutions. Journal of Ecological Engineering, 21, 2, 29-38. DOI: 10.12911/22998993/116351

42. Trus I.M., Fleisher H.Y., Tokarchuk V.V., Gomelya M.D., Vorobyova V.I. 2017. Utilization of the residues obtained during the process of purification of mineral mine water as a component of binding materials. Voprosy Khimii i Khimicheskoi Tekhnologii, 6, 104-109.

43. Trus I.M., Gomelya M.D. 2021. Desalination of mineralized waters using reagent methods. Journal of Chemistry and Technologies, 29(3), 417-424. DOI: $10.15421 /$ jchemtech.v29i3.214939

44. Trus I., Halysh V., Gomelya M., Radovenchyk V. 2021. Low-Waste Technology for Water Purification from Iron Ions. Ecol. Eng. Environ. Technol., 22(4), 116-123. DOI: 10.12912/27197050/137860

45. Trus I.M., Gomelya M.D., Makarenko I.M., Khomenko A.S., Trokhymenko G.G. 2020. The Study of the particular aspects of water purification from heavy metal ions using the method of nanofiltration. Naukovyi Visnyk Natsionalnogo Hirnychogo Universytety, 4, 117-123. DOI: 10.33271/ nvngu/2020-4/117

46. Trus I., Gomelya N., Halysh V., Radovenchyk I., Stepova O., Levytska O. 2020. Technology of the comprehensive desalination of wastewater from mines. Eastern-European Journal of Enterprise Technologies, 3/6, 105, 21-27. DOI: 10.15587/1729-4061.2020.206443

47. Trus I., Gomelya N., Trokhymenko G., Magas N., Hlushko O. 2019. Determining the influence of the medium reaction and the technique of magnetite modification on the effectiveness of heavy metals sorption. Eastern-European Journal of Enterprise Technologies, 6/10(102), 49-54. doi. org/10.15587/1729-4061.2019.188295

48. URL: http://www. aquaphor.ua/aqualen

49. Vardhan K.H., Kumar P.S., Panda R.C. 2019. A review on heavy metal pollution, toxicity and remedial measures: Current trends and future perspectives, Journal of Molecular Liquids, 290. DOI: 10.1016/j. molliq.2019.111197

50. Walczak A. 2021. The Use of World Water Resources in the Irrigation of Field Cultivations. Journal of Ecological Engineering. 22(4), 186-206. DOI: $10.12911 / 22998993 / 134078$ 